\title{
Coral recruitment of a subtropical coral community at Yenliao Bay, northern Taiwan
}

\author{
Ming-Jay Ho and Chang-Feng Dai
}

\begin{abstract}
Background: The subtropical coral community at Yenliao Bay $\left(25^{\circ} 3^{\prime} \mathrm{N}, 121^{\circ} 56^{\prime} \mathrm{E}\right)$, northern Taiwan, is distinguished from tropical reefs by low species diversity, low coral cover, and limited reef-building activities. Coral recruitment in this community was hypothesized to be lower due to features of marginal environment.

Results: We studied the seasonal variations of coral recruitment at Yenliao Bay from May 2006 to September 2009. Two groups of ceramic plates were deployed at three reefs with one group retrieved at 3-month intervals and the other at 1-year intervals. Coral recruits in Yenliao Bay were found only in summer and early autumn (from June to October) corresponding to the reproductive season of corals in this area. The taxonomic composition of coral recruits was dominated by Pocilloporidae (52\% to $90 \%$ ) and Acroporidae (10\% to $41 \%$ ). Recruitment rates varied greatly in four consecutive years, ranging from $8.0 \pm 3.1$ recruits $\mathrm{m}^{-2}$ (mean $\pm \mathrm{SE}$ ) in 2008 to $116.4 \pm 42.4$ recruits $\mathrm{m}^{-2}$ in 2006. The survival rate of coral recruits after 1 year was approximately $12 \%$, and acroporid recruits had a higher survival rate. Most of the coral recruits settled on top and vertical surfaces in contrast to the preference of bottom surface in tropical reefs. Furthermore, there was a negative correlation between the number of recruits and depths.

Conclusions: Coral recruitment at Yenliao Bay occurred in summer and early autumn. The high recruitment rates in 2006 and 2007 were comparable with those of tropical reefs, suggesting that recruitment might not be a limiting factor for the maintenance and development of local coral communities. The number of coral recruits on top and vertical surfaces was negatively correlated with depths, suggesting that light intensity is possibly the primary factor controlling settlement and survival of coral recruits in subtropical coral communities.
\end{abstract}

Keywords: Coral recruitment; Subtropical coral community; Yenliao Bay; Northern Taiwan

\section{Background}

Coral recruitment has been recognized as the critical process in determining the robustness and resilience of coral reef systems, especially when such systems are subjected to threats or damages (Gittings et al. 1988; Hughes and Tanner 2000; Kojis and Quinn 2001). Recruitment is also a key factor for understanding the population dynamics and community structures in these ecosystems (Caley et al. 1996; Quinn and Kojis 2003; Glassom et al. 2004). Hence, it is widely recognized that investigating the patterns of coral recruitment is essential for reef conservation and management practices. However, insufficient attention has been paid to understand the recruitment

\footnotetext{
* Correspondence: corallab@ntu.edu.tw

Institute of Oceanography, National Taiwan University, Taipei 10617, Taiwan
}

processes in marginal coral communities (Harriott and Banks 2002; Hoey et al. 2011).

Coral recruitments have been intensively studied in different geographic regions during the past three decades (e.g., Birkeland 1977; Harriott 1992; Hughes et al. 1999; Soong et al. 2003; Glassom et al. 2004; Nozawa et al. 2006; Adjeroud et al. 2007; Salinas-de-León et al. 2013). These studies have pointed out that recruitment rates are highly variable on spatial and temporal scales. Recruitment rates vary with geographical positions, depth, light availability, substrate topography, biotic interactions, and other biophysical factors (Birkeland 1977; Maida et al. 1995; Babcock and Mundy 1996; Hughes et al. 1999; Glassom et al. 2004). Hughes et al. (2002) reported that recruitment rates of corals decreased with increasing latitudes in the Great Barrier Reef. Other studies, however, showed that there was no consistent pattern in recruitment rates 
between subtropical and tropical reefs (Harriott 1992; Harriott and Simpson 1997; Glassom et al. 2006). Several studies have showed that recruitment rates on subtropical reefs are highly variable in both spatial and temporal scales (Harriott and Banks 1995; Tioho et al. 2001; Glassom et al. 2004). The recruitment of broadcast-spawning corals were reported to decline toward higher latitudes (Harriott 1999; Hughes et al. 2002), while the opposite trend was found among brooding corals, resulting in the dominance of brooders at higher latitudes (Glassom et al. 2004, 2006; Tioho et al. 2001; Nozawa et al. 2006).

Coral communities in Yenliao Bay are typical marginal coral communities characterized by low coral coverage and limited reef-building activity (Yang and Dai 1982). The main environmental conditions restricting reef development are possibly low sea temperature, strong northeast monsoon, and high turbidity in winter. Soong et al. (2003) showed that coral recruitment rate was very low in northern Taiwan based on the surveys conducted in March to May. This low recruitment rate may be responsible for the low species diversity and may constrain the resilience of this marginal coral community. However, Soong et al. (2003) did not examine coral recruitment in other months, especially during the spawning season of corals in northern Taiwan which was reported to occur in June and July (Dai et al. 1992). Thus, more comprehensive studies of coral recruitment in this area are needed. Furthermore, this subtropical coral community may become the refuge of tropical coral species under the impacts of climate change (Tsai et al. 2005). However, this will be mainly determined by the availability of coral recruitments in subtropical coral communities. In this study, we investigated the patterns of coral recruitment at Yenliao Bay in northern Taiwan with an aim to reveal the recruitment pattern and to examine whether the recruitment rate is the major limiting factor for the maintenance and development of coral communities.

\section{Methods}

\section{Study site}

Yenliao Bay $\left(25^{\circ} 2^{\prime} \mathrm{N}, 121^{\circ} 56^{\prime} \mathrm{E}\right)$ is a semi-enclosed bay located on the northern coast of Taiwan (Figure 1).

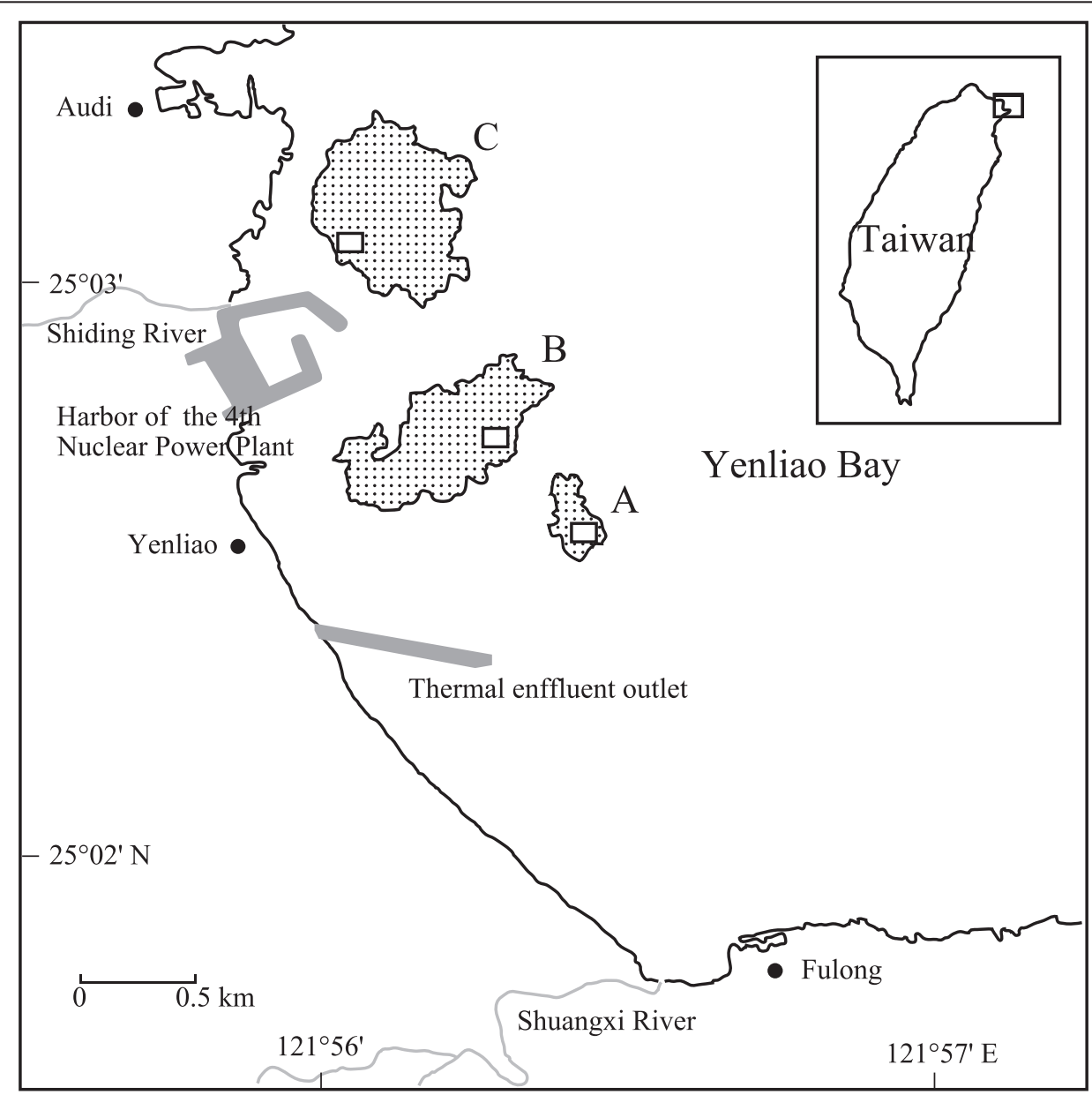

Figure 1 Map of the study area. It shows three sampling sites (blank squares with depth range in brackets) on three rocky reefs (dotted areas designated as $A, B, C)$ for coral recruitment studies. 


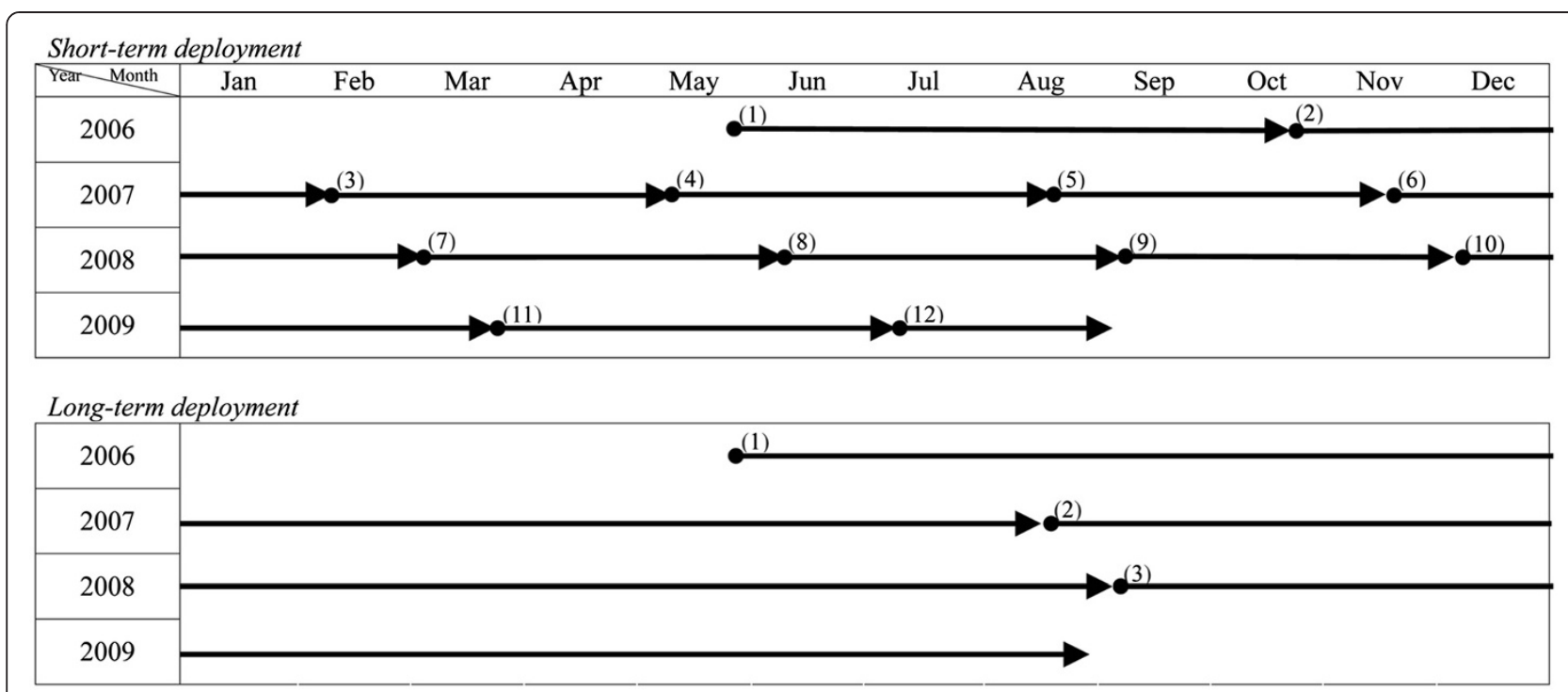

Figure 2 Time frame of deployments and retrievals of settlement plates. They are for 12 short-term ( 2 to 5 months) and three long-term (11 to 15 months) settling plates in 2006 to 2009.

Three rocky reefs (designated as $\mathrm{A}, \mathrm{B}$, and C) separated by sandy bottom were distributed at depths between 0 and $15 \mathrm{~m}$. A total of 106 coral species were found on these reefs, and the coral communities were dominated by faviid, agariciid, and pectiniid corals, and the living cover of scleractinian corals ranged from 5\% to 30\% (Yang and Dai 1982). The species diversity of these communities is relatively low compared with those in southern Taiwan, and no limestone buildup was noticed on these reefs (Dai 1997). Major environmental factors that restrict coral growth and reef development include low sea temperature in winter, heavy sedimentation, and low light intensity (Yang and Dai 1982; Dai et al. 1992).

\section{Recruitment study}

Two groups of settlement plates for short-term and longterm surveys, respectively, were repeatedly deployed at sites A, B, and C from 2006 to 2009 (Figure 2). For shortterm surveys, the settlement plates were deployed and retrieved in approximately 3 -month intervals, and the aim was to investigate the seasonal pattern of coral recruitment including recruitment rate, temporal variations, and taxonomic composition. For long-term surveys, the plates were deployed and retrieved in approximately 1-year intervals, and the aim was to study the survival rate of coral recruits. Coral recruits settled on plates deployed for 1-year intervals was assumed to be comparable to those settled on plates deployed for 3-month intervals in the same time. Therefore, the survival rate could be assessed as recruitment rate of the long-term survey divided by that of the short-term survey in the spawning season. For each group of survey, a total of 10 sets of settlement plates were installed at sites A (three sets), B (three sets), and C (four sets), at depths 12 to 13,8 to 10 , and 6 to $8 \mathrm{~m}$, respectively. Each set of settlement plates comprised four ceramic tiles attached horizontally to a stainless steel frame with approximately $10 \mathrm{~cm}$ between them and was anchored to the substrata with approximately $20 \mathrm{~cm}$ above the sea floor (Figure 3). The unglazed ceramic tiles $(12 \times 12 \times 1 \mathrm{~cm})$ used in Harriott and Fisk (1987) were applied as the settlement plates for coral recruitment studies. These ceramic tiles have been showed to be effective in attracting coral recruits and have been widely applied in coral recruitment studies (Harriott 1999).

All retrieved plates were preserved in 95\% alcohol for further lab examination. Each plate was checked under a dissecting microscope for coral recruits, and all coral

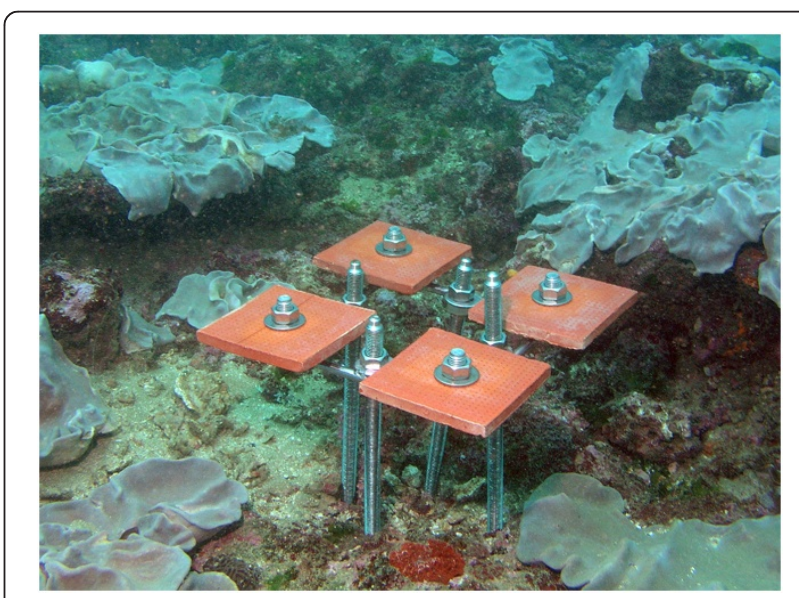

Figure $3 \mathrm{~A}$ set of settlement plates used for coral recruitment surveys in this study. 


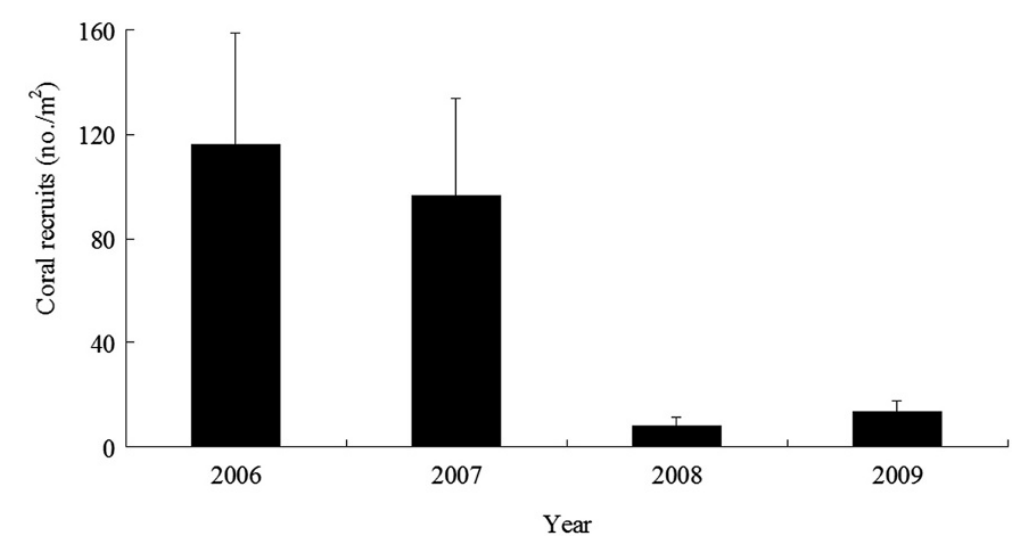

Figure 4 Coral recruitment rate (mean \pm SE) in Yenliao Bay in 2006 to 2009. Data of short-term plates from three study sites (A, B, C) were pooled for comparison.

recruits were counted and identified to family level if possible (Baird and Babcock 2000; Babcock et al. 2003). Positions of coral recruits on the plate surfaces (top, lower, or vertical) were also recorded.

\section{Data analysis}

Statistical analyses were conducted using SPSS 16 (SPSS Inc., Chicago, IL, USA) and StatView 5.0.1 (SAS Institute Inc., Cary, NC, USA). The recruitment data were first tested for homogeneity and normality. In case of nonnormality and heterogeneity of the data, a non-parametric Kruskal-Wallis rank test was applied to examine variations in number of coral recruits among years, sites, and plate surfaces. Mann-Whitney U test with Bonferroni correction as post hoc test was then used for the multiple comparisons since it is an efficient and robust method for heterogeneous data. In addition, the relationship between total number of coral recruits on different surfaces of settlement plates and depths was examined using correlation and linear regression analyses.

\section{Results and discussion \\ Results \\ Coral recruitment and timing}

A total of 298 coral recruits were found on settlement plates in 12 short-term surveys in 2006 to 2009 . The total numbers of coral recruits in each year (sites combined) varied significantly among the four consecutive years
(Figure 4, Table 1 part a; Kruskal-Wallis test, $p<0.0001$ ). Recruitment rate was the highest in June to October 2006 $\left(116.4 \pm 42.4\right.$ recruits $\mathrm{m}^{-2}$, mean $\left.\pm \mathrm{SE}\right)$, followed by that in May to August $2007\left(86.9 \pm 36.0\right.$ recruits $\left.\mathrm{m}^{-2}\right)$ (Figure 5). Recruitment rates were lower than $12.1 \pm 4.1$ recruits $\mathrm{m}^{-2}$ in the other five short-term surveys, and no coral recruit was observed in the rest of the surveys (Figure 5). Recruitment rate also showed a significant difference among years at each study site, except site A (Table 1 part b). No difference was found in recruitment rates among study sites in each year, except that in 2007 (Table 1 part c).

For long-term surveys, the recruitment rate on plates deployed from May 2006 to August 2007 was $13.7 \pm 3.8$ recruits $\mathrm{m}^{-2}$. This rate was only $c a .12 \%$ in comparison with that of the short-term survey in May to August 2006. The recruits recorded in the following two longterm surveys (August 2007 to September 2008 and September 2008 to August 2009) were regarded as newly settled recruits because the time of deployment was in early autumn and all the recruits were comparable or smaller than those recorded in short-term surveys. Therefore, these two surveys were excluded for further analysis.

\section{Taxonomic composition}

Of the 298 coral recruits identified over the 3.6-year study period, the most dominant corals were species of

Table 1 Summary of statistical tests for comparisons of recruitment rates

\begin{tabular}{|c|c|c|c|c|c|c|c|c|c|c|c|c|c|c|c|c|c|c|c|c|c|c|c|c|}
\hline & \multirow{2}{*}{\multicolumn{3}{|c|}{$\begin{array}{c}\text { Part a } \\
\text { Among years }\end{array}$}} & \multicolumn{9}{|c|}{ Part b } & \multicolumn{12}{|c|}{ Part c } \\
\hline & & & & \multicolumn{3}{|c|}{ Site $A$} & \multicolumn{3}{|c|}{ Site B } & \multicolumn{3}{|c|}{ Site C } & \multicolumn{3}{|c|}{2006} & \multicolumn{3}{|c|}{2007} & \multicolumn{3}{|c|}{2008} & \multicolumn{3}{|c|}{2009} \\
\hline & $\overline{d f}$ & $H$ & $p$ & $\overline{d f}$ & $H$ & $p$ & $\overline{d f}$ & $H$ & $p$ & $\overline{d f}$ & $H$ & $p$ & $\overline{d f}$ & $H$ & $p$ & $\overline{d f}$ & $H$ & $p$ & $\overline{d f}$ & $H$ & $p$ & $d f$ & $H$ & $p$ \\
\hline Years & 3 & 22.95 & $<0.00001^{*}$ & 3 & 6.51 & 0.09 & 3 & 9.46 & $0.02^{*}$ & 3 & 8.12 & $0.04^{*}$ & & & & & & & & & & & & \\
\hline Site & & & & & & & & & & & & & 2 & 4.41 & 0.11 & 2 & 6.56 & $0.04^{*}$ & 2 & 4.00 & 0.14 & 2 & 1.01 & 0.60 \\
\hline
\end{tabular}

Part a, among years (three sites combined); part b, among years at each site; part c, among sites in each year. Kruskal-Wallis rank test, ${ }^{*} p<0.05$ is significant. 


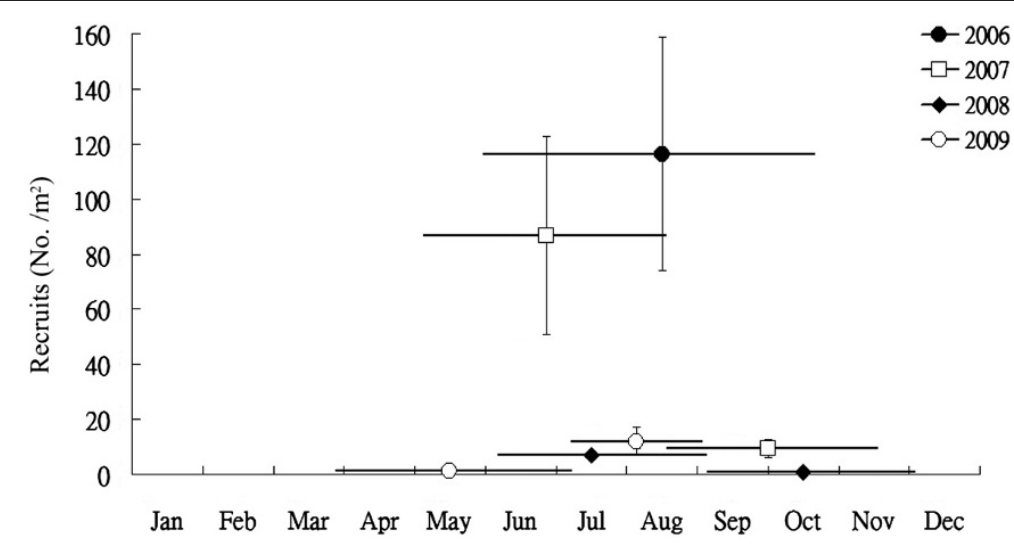

Figure 5 Density of coral recruits (mean $\pm \mathrm{SE}, \boldsymbol{n}=\mathbf{3}$ ) on 12 short-term plates in 2006-2009. Horizontal bars denote the deployment duration of settlement plates. Five sets with no recruits were omitted.

family Pocilloporidae which constituted $52 \%$ to $90 \%$ of total recruits in each year (Figure 6), followed by species of family Acroporidae ( $10 \%$ to $41 \%)$. Other recruits of families Poritidae and Faviidae were rare. However, on the settlement plates of long-term deployment from May 2006 to August 2007, coral recruits of family Acroporidae were the dominant one (77\%), followed by Pocilloporidae (18\%) and Poritidae (6\%) (Figure 6).

\section{Coral recruits on different surfaces}

Regarding the number of coral recruits on different surfaces of the settlement plates, the majority $(53 \%, n=158)$ were found on the top surface, followed by $42 \%(n=125)$ on the vertical surface, and $5 \%(n=15)$ on the bottom surface (Figure 7). On the plates of long-term surveys, coral recruits were found on top and vertical surfaces, and no recruit was found on the bottom surface. The recruitment rates on different surfaces of the plates were significantly different
(Table 2 part a, Kruskal-Wallis test, $p<0.0001$ ). Among years, the recruitment rates differed significantly only in 2006 and 2007 (Table 2 part b, Kruskal-Wallis test, $p<0.01$ ). Furthermore, the recruitment rates on top and vertical surfaces were significantly higher than those on bottom surfaces in 2006 and 2007 (Table 2 part c, Mann-Whitney $\mathrm{U}$ test with Bonferroni correction, $p<0.01, p<0.001$ ).

\section{Recruitment rates and depths}

Since most of the coral recruits occurred in two shortterm surveys (May to October 2006 and May to August 2007), these data were applied to show the relationship between depths and recruitment rates on different surfaces. The total number of recruits per plate was negatively correlated with depth (Figure 8 , Table $3 ; p=0.0001$ ). In addition, among the three surfaces of plates, the recruitment rates on top and vertical surfaces were negatively correlated with depths (Table $3 ; p<0.05, p<0.0001$ ).

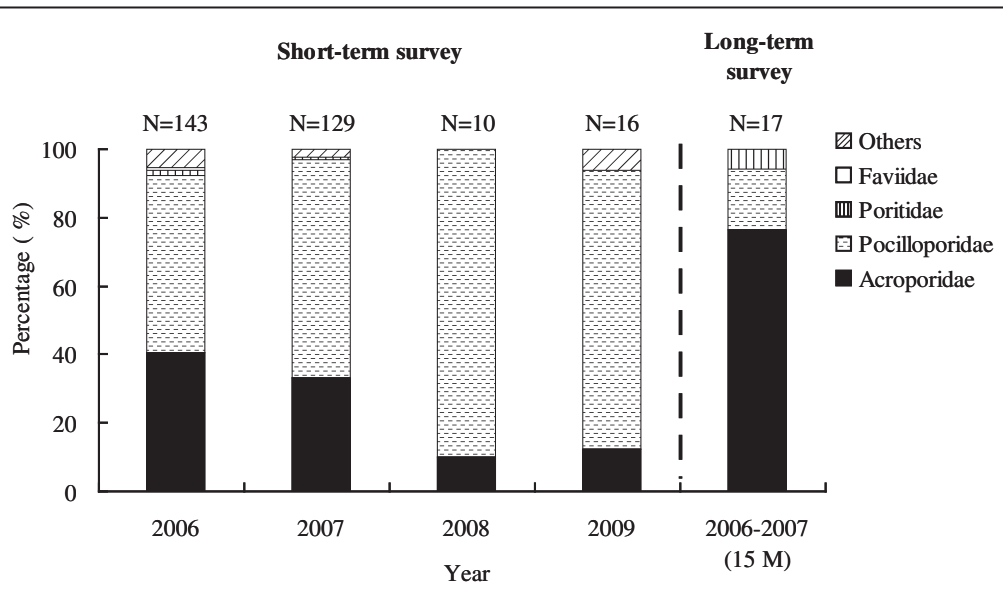

Figure 6 Taxonomic composition of coral recruits. They are based on 12 groups of short-term plates and 1 group of long-term survey (15 months; May 2006 to August 2007). Data from the three study sites were pooled. Numbers of coral recruits were shown above each bar. 


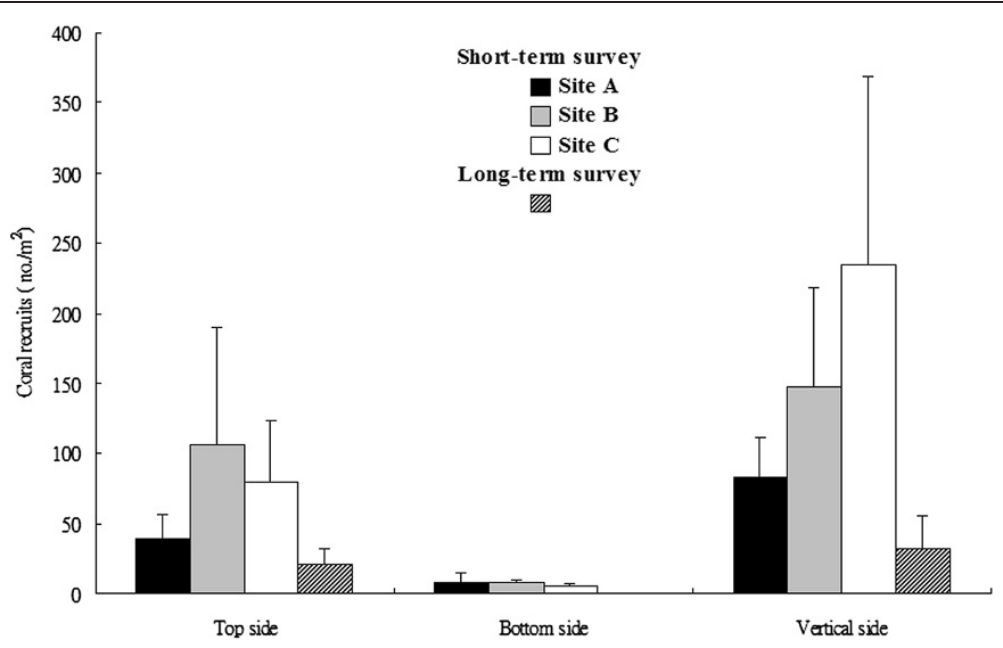

Figure 7 Coral recruits (mean \pm SE) on top, bottom, and vertical sides of the settlement plates. They are from 12 groups of short-term surveys and 1 long-term survey. Data of the short-term surveys at each study site were pooled among years ( $n=4,2006$ to 2009). Data from the long-term survey were pooled among the three study sites (A, B, C).

\section{Discussion}

\section{Coral recruitment rates}

During the 4-year study period, coral recruitments peaked in summer and early autumn (June to October) in each year (Figure 5). This timing of coral recruits is consistent with the reproductive season of corals in northern Taiwan which has been showed to occur in early June and July (Dai et al. 1992; Fan and Dai 1995). Coral recruitment rates in this study were about five times higher than those reported by Soong et al. (2003) in northeastern Taiwan. This difference was mainly due to the timing of plate deployment since the survey of Soong et al. (2003) was conducted in April to May, about 2 months before the reproductive season of corals in northeastern Taiwan (Dai et al. 1992).

Coral recruitment rates varied greatly among the four consecutive reproductive seasons with significantly higher values found in 2006 and 2007 (Figure 4). Many studies have showed great variations of coral recruitment at different spatial and temporal scales (Table 4), especially in high-latitude coral communities (Harriott and Banks 1995; Tioho et al. 2001; Glassom et al. 2004).
The variation of coral recruitments may be related to the greater variations of environmental factors such as sea temperature and light intensity. Previous studies indicated that wintertime sea temperature in Yenliao Bay occasionally fell below $18^{\circ} \mathrm{C}$, and corals in northern Taiwan spawned in the summer during the periods of maximum sea temperatures (Yang and Dai 1982; Dai et al. 1992). Wintertime sea temperature in the study area was below $18^{\circ} \mathrm{C}$ in 2008 (minimum $13.3^{\circ} \mathrm{C}$ in February), and the rise of maximum sea temperatures delayed for almost 2 months in 2008 and 2009 (Figure 9). The delay of seawater temperature rising may have significant influences on coral reproduction. Nozawa (2012) reported that the exact timing of spawning in a subtropical coral community varied among years and was correlated with the cumulative seawater temperature during the late period of gametogenesis ( 0 to 3 months before spawning). The lower seawater temperature and delayed rising of seawater temperature in 2008 and 2009 might have significant impacts on coral reproduction by delaying the spawning time in Yenliao Bay.

Table 2 Summary of statistical tests for comparisons of recruitment rates

\begin{tabular}{|c|c|c|c|c|c|c|c|c|c|c|c|c|c|c|c|c|c|c|c|c|c|}
\hline & \multirow{2}{*}{\multicolumn{3}{|c|}{ Part a }} & \multicolumn{12}{|c|}{ Part b } & \multicolumn{6}{|c|}{ Part c } \\
\hline & & & & \multicolumn{3}{|c|}{2006} & \multicolumn{3}{|c|}{2007} & \multicolumn{3}{|c|}{2008} & \multicolumn{3}{|c|}{2009} & \multicolumn{3}{|c|}{2006} & \multicolumn{3}{|c|}{2007} \\
\hline & $\overline{d f}$ & $F$ & $p$ & $d f$ & $H$ & $p$ & $\overline{d f}$ & $H$ & $p$ & $\overline{d f}$ & $H$ & $p$ & $d f$ & $H$ & $p$ & $d f$ & $z$ & $p$ & $\overline{d f}$ & $Z$ & $p$ \\
\hline Surfaces & 2 & 21.55 & $<0.0001^{*}$ & 2 & 13.17 & $<0.01^{*}$ & 2 & 21.49 & $<0.0001^{*}$ & 2 & 2.11 & 0.35 & 2 & 1.35 & 0.51 & & & & & & \\
\hline T vs. B & & & & & & & & & & & & & & & & 9 & -3.00 & $<0.01^{*}$ & 9 & -3.66 & $<0.001^{*}$ \\
\hline B vs. V & & & & & & & & & & & & & & & & 9 & -3.27 & $<0.01^{*}$ & 9 & -3.87 & $<0.001^{*}$ \\
\hline T vs. V & & & & & & & & & & & & & & & & 9 & -0.34 & 0.73 & 9 & -2.42 & $0.015^{*}$ \\
\hline
\end{tabular}

Part a, among surfaces (top, bottom, and vertical) in 2006 to 2009 , Kruskal-Wallis rank test; ${ }^{*} p<0.05$ is significant. Part b, among surfaces, Kruskal-Wallis rank test; ${ }^{*} p<0.05$ is significant. Part $c$, among surfaces (T, top; B, bottom; $\mathrm{V}$, vertical), Mann-Whitney U test with Bonferroni correction; ${ }^{*} p<0.0167$ is significant. 


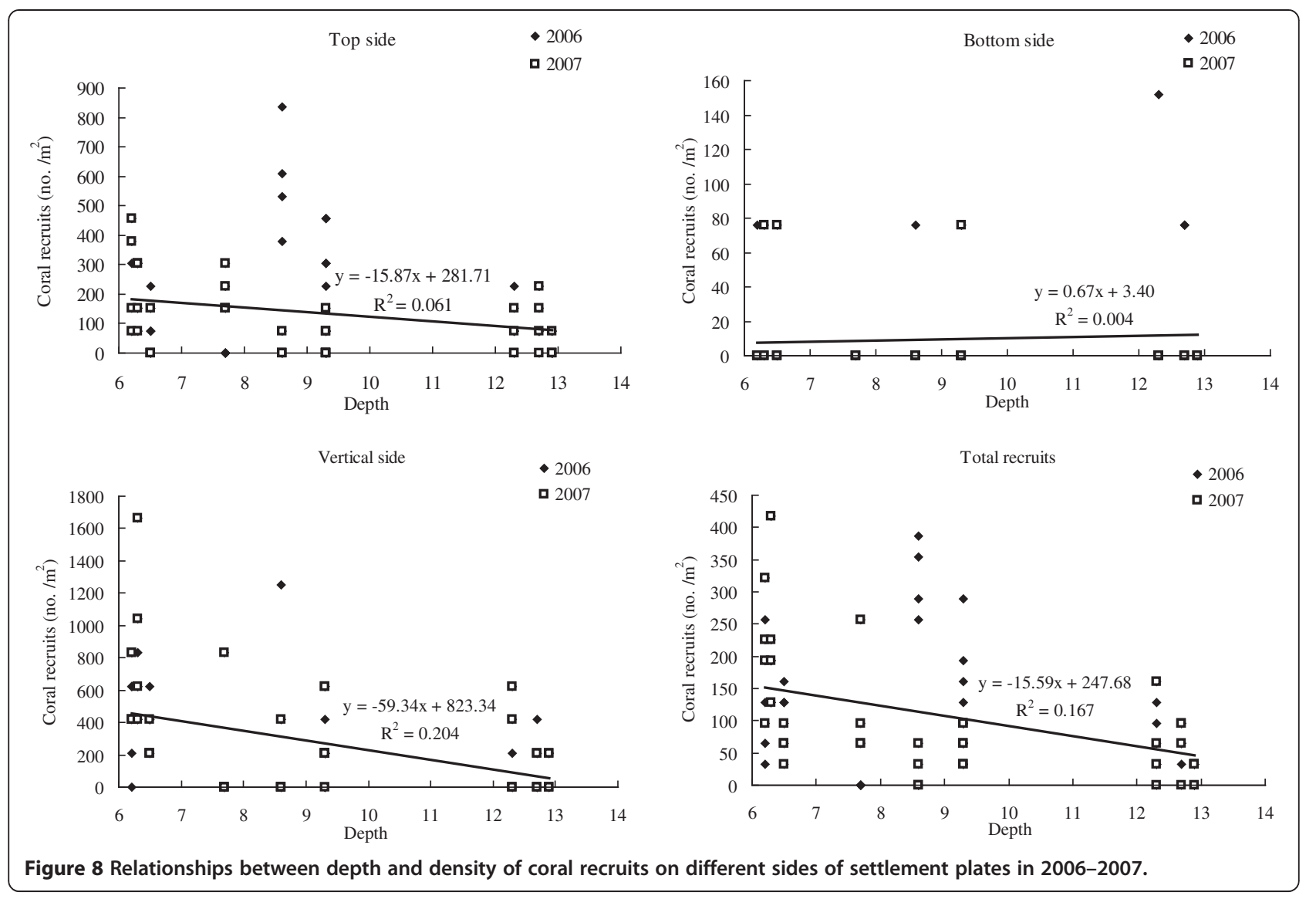

The recruitment rates of coral communities at Yenliao Bay in 2006 and 2007 were comparable with those reported from other high-latitude or marginal areas of the world (Table 4). The lower recruitment rates in 2008 and 2009 were similar to those recorded in high-latitude coral communities in southern Japan (Tioho et al. 2001; Nozawa et al. 2006). Furthermore, the survival rate of coral recruits in Yenliao Bay from 2006 to 2007 was also comparable with that reported in southern Japan (Nozawa et al. 2006). Based on similar recruitment and survival rates, Harriott (1999) suggested that the low recruitment rates should be sufficient to maintain the high-latitude coral communities. Moreover, the recruitment rates of corals at Yenliao Bay in 2006 and 2007 were higher than that reported in a tropical reef in Nanwan Bay (32.5 spats $\mathrm{m}^{-2}$ ), southern Taiwan (Kuo and Soong 2010). Therefore, it seems that the recruitment rate is not a limiting factor for the maintenance and development of coral communities in Yenliao Bay.

\section{Taxonomic composition}

Pocilloporid corals were the most abundant recruits during the study period (Figure 6), and most of the recruits were possibly Stylophora pistillata, the common pocilloporid coral in Yenliao Bay (Yang and Dai 1982). This is consistent with the pattern of high-latitude coral communities where brooding corals (mainly pocilloporids) are the most abundant recruits (Tioho et al. 2001; Hughes et al. 2002; Glassom et al. 2004, 2006; Nozawa et al. 2006). It seems that brooding pocilloporids release planulae only in summer and early autumn in northern Taiwan, while they have extended reproductive season throughout the year in southern Taiwan (Dai et al. 1992). The short pre-competent period of brooding larvae may result in high contribution to local recruitment of high-latitude coral communities (Harriott 1992; Tioho et al. 2001). The recruits of acroporid corals were less than those of pocilloporids in short-term surveys, while they became the most abundant in long-term surveys. This is possibly due to the higher survivorship of

Table 3 Correlation analyses ( $Z$ test) between depths and number of coral recruits on different surfaces of plates

\begin{tabular}{lll}
\hline Groups & $\boldsymbol{Z}$ value & $\boldsymbol{p}$ value \\
\hline Depth vs. top surface & -2.21 & $0.027^{*}$ \\
Depth vs. bottom surface & 0.53 & 0.599 \\
Depth vs. vertical surface & -4.27 & $<0.0001^{*}$ \\
Depth vs. total recruits & -3.81 & $0.0001^{*}$ \\
\hline
\end{tabular}

Data of 2006 and 2007 combined. $n=80$ plates; ${ }^{*} p<0.05$ is significant. 


\begin{tabular}{|c|c|c|c|c|c|}
\hline Region & Latitude & Material & $\begin{array}{l}\text { Recruitment rate } \\
\left(\text { number } \mathrm{m}^{-2} \text { year }^{-1}\right)\end{array}$ & Location & Source \\
\hline \multirow[t]{2}{*}{ North Pacific } & $32^{\circ} \mathrm{N}$ & Slate & 2 & Amakusa, Japan & Nozawa et al. (2006) \\
\hline & $25^{\circ} \mathrm{N}$ & Ceramic & 106 & Yenliao Bay, northern Taiwan & This study \\
\hline \multirow[t]{2}{*}{ South Pacific } & $29-30^{\circ} \mathrm{S}$ & Ceramic & 132 & Solitary Islands, Eastern Australia & Harriott and Banks (1995) \\
\hline & $26^{\circ} \mathrm{S}$ & Ceramic & 173 & Gneering Shoals, Australia & Banks and Harriott (1996) \\
\hline Caribbean & $10^{\circ} \mathrm{N}$ & & 3.8 & Cubagua Island, Venezuela & Rodrǐguez et al. (2009) \\
\hline \multirow[t]{2}{*}{ Red Sea } & $29^{\circ} \mathrm{N}$ & Ceramic & 18 & Eilat, Israel & Abelson et al. (2005) \\
\hline & $29^{\circ} \mathrm{N}$ & Ceramic & 190 & Eilat, Israel & Glassom et al. (2004) \\
\hline Indian Ocean & $30^{\circ} \mathrm{S}$ & Ceramic & 1,007 & Sodwana Bay, South Africa & Glassom et al. (2006) \\
\hline
\end{tabular}

Coral recruits were calculated following Glassom et al. (2004).

acroporid corals since they tend to form larger spats, and the survivorship of larger spats is often higher than that of smaller spats (Nozawa et al. 2006). However, the branching Acropora colonies were susceptible to storm disturbances; thus, their abundance was relatively low compared with the encrusting and foliaceous colonies of Montipora species in the coral communities at Yenliao Bay (Yang and Dai 1982).

\section{Orientation of recruits}

Coral recruitment patterns may represent the results of habitat selection of pre-settlement larvae (Babcock and Mundy 1996; Kuffner 2001; Baird et al. 2003) and postsettlement factors (Sato 1985; Smith 1997). Most studies on shallow tropical reefs demonstrated that coral recruits had a greater preference for the vertical and bottom surfaces (Harriott and Fisk 1987; Fisk and Harriott 1990; Harrison and Wallace 1990). It is suggested that grazing and sedimentation are the main factors inhibiting the settlement and survival of coral larvae on the top surface (Birkeland 1977; Carleton and Sammarco 1987; Fisk and Harriott 1990). However, studies on the settlement pattern of subtropical reefs showed that more coral recruits were found on top and vertical surfaces of

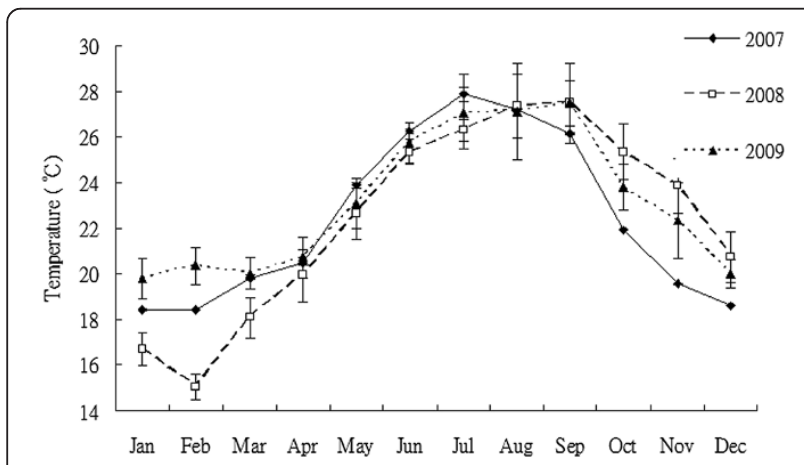

Figure 9 Monthly variations of sea surface temperature (mean \pm SD) in the study area 2007-2009. Courtesy of The Central Weather Bureau, Taiwan. the settlement plates (Harriott and Banks 1995; Banks and Harriott 1996). Harriott and Banks (1995) suggested that the preference of top surface might be due to low light intensity and competition of other benthos.

Light intensity and solar radiation has been suggested to be one of the important factors responsible for the pattern of coral recruitment (Maida et al. 1994; Harriott and Banks 1995). Coral recruits preferred to settle in the position that offered optimal light condition for spat development, and the survivorship and average size of coral recruits were both higher for those settled in the position of the plates with optimal light condition (Maida et al. 1994). The light intensity in subtropical reefs is often lower than that of tropical reefs mainly due to higher water turbidity and lower solar radiation (Harriott and Banks 1995; Harriott and Simpson 1997; Glassom et al. 2006). Under such an environment, light on the lower surface is likely too low to support the photosynthesis of coral larvae which is critical for their survival and growth. Therefore, coral larvae tend to colonize the top surface, and coral recruits that colonize the top surface have a higher survival rate (Maida et al. 1994).

Competition with other benthos for settlement space and post-settlement mortality due to overgrowth of other organisms may also limit coral recruitment on the bottom surface in subtropical reefs (Birkeland 1977; Harriott and Banks 1995). In this study, the bottom surface of settlement plates was frequently occupied by macrobenthos such as bryozoans, ascidians, polychaetes, and barnacles. These cryptic organisms often have higher growth rates and may quickly occupy the bottom surface, thus prohibiting or excluding the settlement of coral recruits (Birkeland 1977).

The number of coral recruits in Yenliao Bay showed a negative correlation with depths (Table 3). Moreover, the number of coral recruits on top and vertical surfaces decreased with increasing depths (Figure 8). Since water turbidity in Yenliao Bay is frequently high due to 
constant input of runoffs from adjacent rivers and resuspension of sediment, light intensity in the water column reduces rapidly with increasing depths. Light availability at different depths is likely the primary factor controlling the settlement pattern of coral recruits in Yenliao Bay.

\section{Conclusions}

We investigated the recruitment pattern of scleractinian corals of a subtropical coral community in northern Taiwan. The recruitment season occurred from summer to early autumn, and this was consistent with the reproductive season of corals in Yenliao Bay. The recruitment rates were highly variable among years and might be influenced by the annual variation of seawater temperatures. The high recruitment rates recorded in 2006 and 2007 were comparable with those of tropical reefs and other subtropical reefs, suggesting that coral recruitment might have the potential to support the maintenance and development of this marginal coral community. Pocilloporid corals were the most abundant recruits, while acroporids had a higher survival rate. Coral recruits settled mainly on the top and vertical surfaces of settlement plates, and the number of coral recruits was negatively correlated with depths, suggesting that light intensity might be the primary factor affecting the settlement and survival of coral recruits.

\section{Competing interests}

The authors declare that they have no competing interests.

\section{Authors' contributions}

MJH participated in the experimental design, carried out the field and lab works, performed data analyses and drafted the manuscript. CFD designed the experiments, participated part of the field and lab works, instructed data analyses, edited and finalized the manuscript. Both authors read and approved the final manuscript.

\section{Acknowledgements}

We are grateful to Dr. YR Cheng, Mr. S Chang, C Chou, J Chou, P Huang, C Liu, R Shiu, and members of Coral Lab at Institute of Oceanography, National Taiwan University for their assistance with field work. We would like to thank two anonymous reviewers for their helpful suggestions. This study was supported in part by a grant from Taiwan Power Company.

Received: 14 August 2013 Accepted: 20 December 2013

Published: 24 January 2014

\section{References}

Abelson A, Olinky R, Gaines S (2005) Coral recruitment to the reefs of Eilat, Red Sea: temporal and spatial variation, and possible effects of anthropogenic disturbances. Mar Poll Bull 50:576-582

Adjeroud M, Penin L, Carroll A (2007) Spatio-temporal heterogeneity in coral recruitment around Moorea, French Polynesia: implications for population maintenance. J Exp Mar Bio Ecol 341:204-218

Babcock RC, Mundy C (1996) Coral recruitment: consequences of settlement choice for early growth and survivorship in two scleractinians. J Exp Mar Bio Ecol 206:179-201

Babcock RC, Baird AH, Piromvaragorn S, Thomson DP, Willis BL (2003) Identification of scleractinian coral recruits from Indo-Pacific reefs. Zool Stud 42:211-226

Baird AH, Babcock RC (2000) Morphological differences among three species of newly settled pocilloporid coral recruits. Coral Reefs 19:179-183
Baird AH, Babcock RC, Mundy CP (2003) Habitat selection by larvae influences the depth distribution of six common coral species. Mar Ecol Prog Ser 252:289-293

Banks SA, Harriott VJ (1996) Patterns of coral recruitment at the Gneering Shoals, southeast Queensland, Australia. Coral Reefs 15:225-230

Birkeland C (1977) The importance of rate of biomass accumulation in early successional stages of benthic communities to the survival of coral recruits. Proc 3rd Int Coral Reef Symp 1:15-21

Caley MJ, Carr MH, Hixon MA, Hughes TP, Jones GP, Menge BA (1996) Recruitment and the local dynamics of open marine populations. Annu Rev Ecol and Syst 27:477-500

Carleton JH, Sammarco PW (1987) Effects of substratum irregularity on success of coral settlement: quantification by comparative geomorphological techniques. Bull Mar Sci 40:85-98

Dai CF (1997) Assessment of the present health of coral reefs in Taiwan. In: Grigg RW, Birkeland C (ed) Status of coral reefs in the pacific. University of Hawaii Sea Grant Program, Honolulu, pp 123-131

Dai CF, Soong K, Fan TY (1992) Sexual reproduction of corals in northern and southern Taiwan. Proc 7th Int Coral Reef Symp 1:448-455

Fan TY, Dai CF (1995) Reproductive ecology of the scleractinian coral Echinopora lamellosa in northern and southern Taiwan. Mar Biol 123:565-572

Fisk DA, Harriott VJ (1990) Spatial and temporal variation in coral recruitment on the Great Barrier Reef: implications for dispersal hypotheses. Mar Biol 107:485-490

Gittings SR, Bright TJ, Choi A, Barnett RR (1988) The recovery process in a mechanically damaged coral reef community: recruitment and growth. Proc 6th Int Coral Reef Symp 2:225-230

Glassom D, Zakai D, Chadwick-Furman NE (2004) Coral recruitment: a spatio-temporal analysis along the coastline of Eilat, northern Red Sea. Mar Biol 144:641-651

Glassom D, Celliers L, Schleyer MH (2006) Coral recruitment patterns at Sodwana Bay, South Africa. Coral Reefs 25:485-492

Harriott VJ (1992) Recruitment patterns of scleractinian corals in an isolated sub-tropical reef system. Coral Reefs 11:215-219

Harriott VJ (1999) Coral recruitment at a high latitude Pacific site: a comparison with Atlantic reefs. Bull Mar Sci 65:881-891

Harriott VJ, Banks SA (1995) Recruitment of scleractinian corals in the Solitary Islands Marine Reserve, a high latitude coral dominated community in eastern Australia. Mar Ecol Prog Ser 123:155-161

Harriott VJ, Banks SA (2002) Latitudinal variation in coral communities in eastern Australia: a qualitative biophysical model of factors regulating coral reefs. Coral Reefs 21:83-94

Harriott VJ, Fisk DA (1987) A comparison of settlement plate types for experiments on the recruitment of scleractinian corals. Mar Ecol Prog Ser 37:201-208

Harriott VJ, Simpson CJ (1997) Coral recruitment on tropical and subtropical reefs in Western Australia. Proc 8th Int Coral Reef Symp 2:1191-1196

Harrison PL, Wallace CC (1990) Reproduction, dispersal and recruitment of scleractinian corals. In: Dubinsky Z (ed) Ecosystems of the world 25: coral reef. Elsevier, Amsterdam, pp 133-207

Hoey AS, Pratchett MS, Cvitanovic C (2011) High macroalgal cover and low coral recruitment undermines the potential resilience of the world's southernmost coral reef assemblages. Plos One 6:e25824. doi:10.1371/journal.pone.0025824

Hughes TP, Tanner JE (2000) Recruitment failure, life histories, and long-term decline of Caribbean corals. Ecology 81:2250-2263

Hughes TP, Baird AH, Dinsdale EA, Moltschaniwskyj N, Pratchett MS, Tanner JE, Willis B (1999) Patterns of recruitment and abundance of corals along the Great Barrier Reef. Nature 397:59-63

Hughes TP, Baird AH, Dinsdale EA, Harriott VJ, Moltschaniwskyj NA, Pratchett MS, Tanner JE, Willis BL (2002) Detecting regional variation using meta-analysis and large-scale sampling: latitudinal patterns in recruitment. Ecology 83:436-451

Kojis BL, Quinn NJ (2001) The importance of regional differences in hard coral recruitment rates for determining the need for coral restoration. Bull Mar Sci 69:967-974

Kuffner I (2001) Effects of ultraviolet radiation (UV) on larval settlement of the reef coral Pocillopora damicornis. Mar Ecol Prog Ser 217:251-261

Kuo KM, Soong K (2010) Post-settlement survival of reef-coral juveniles in southern Taiwan. Zool Stud 49:724-734

Maida MJ, Coll C, Sammarco PW (1994) Shedding light on scleractinian coral recruitment. J Exp Mar Biol Ecol 180:189-202

Maida M, Sammarco PW, Coll JC (1995) Effects of soft corals on scleractinian coral recruitment. I: directional allelopathy and inhibition of settlement. Mar Ecol Prog Ser 121:191-202 
Nozawa Y (2012) Annual variation in the timing of coral spawning in a high-latitude environment: influence of temperature. Biol Bull 222:192-202

Nozawa Y, Tokeshi M, Satoshi N (2006) Reproduction and recruitment of scleractinian corals in a high-latitude coral community, Amakusa, southwestern Japan. Mar Biol 149:1047-1058

Quinn NJ, Kojis BL (2003) The dynamics of coral reef community structure and recruitment patterns around Bota, Saipan, and Tinian, Western Pacific. Bull Mar Sci 72:979-996

Rodrǐguez S, Alvizu A, Tagliafico A, Bastidas C (2009) Low natural repopulation of marginal coral communities under the influence of upwelling. Hydrobiologia 624:1-11

Salinas-de-León P, Dryden C, Smith DJ, Bell JJ (2013) Temporal and spatial variability in coral recruitment on two Indonesian coral reefs: consistently lower recruitment to a degraded reef. Mar Biol 160:97-105

Sato M (1985) Mortality and growth of juvenile coral Pocillopora damicornis (Linnaeus). Coral Reefs 4:27-33

Smith SR (1997) Patterns of coral settlement, recruitment and juvenile mortality with depth at Conch Reef, Florida. Proc 8th Int Coral Reef Symp 2:1197-1202

Soong K, Chen MH, Chen CL, Dai CF, Fan TYLJJ, Fan HM (2003) Spatial and temporal variation of coral recruitment in Taiwan. Coral Reefs 22:224-228

Tioho H, Tokeshi M, Nojima S (2001) Experimental analysis of recruitment in a scleractinian coral at high latitude. Mar Ecol Prog Ser 213:79-86

Tsai WS, Dai CF, Yang IC, Tung CP (2005) Using genetic programming to modeling spatial distribution of corals and the impacts of climatic changes: a case study from Taiwan. In: Proceedings of 10th International Coral Reef Symposium, Okinawa. ReefBase, Penang, pp 1440-1444

Yang RT, Dai CF (1982) Coral communities in Yenliao Bay, Taiwan. Acta Oceanogr Taiwanica 13:167-180

doi:10.1186/1810-522X-53-5

Cite this article as: $\mathrm{Ho}$ and Dai: Coral recruitment of a subtropical coral community at Yenliao Bay, northern Taiwan. Zoological Studies 2014 53:5.

\section{Submit your manuscript to a SpringerOpen ${ }^{\circ}$ journal and benefit from:}

- Convenient online submission

- Rigorous peer review

- Immediate publication on acceptance

- Open access: articles freely available online

- High visibility within the field

- Retaining the copyright to your article

Submit your next manuscript at $>$ springeropen.com 